\title{
Coming home may hurt: risk factors for mental ill health in US reservists after deployment in Iraq
}

\author{
Lyndon A. Riviere, Athena Kendall-Robbins, Dennis McGurk, Carl A. Castro and Charles W. Hoge
}

\section{Background}

Little research has been conducted on the factors that may explain the higher rates of mental health problems in United States National Guard soldiers who have deployed to the Iraq War.

\section{Aims \\ To examine whether financial hardship, job loss, employer support and the effect of deployment absence on co-workers were associated with depression and post-traumatic stress disorder (PTSD). \\ Method \\ Cross-sectional data were obtained from 4034 National Guard soldiers at two time points. All measures were assessed by self-report.}

\section{Results}

The four factors were associated with depression and PTSD, with variability based on outcome and time point. For example, job loss increased the odds of meeting criteria for depression at 3 and 12 months and for PTSD at 12 months; the negative effect of deployment absence on co-workers increased the likelihood of meeting criteria for PTSD, but not depression, at both time points.

\section{Conclusions}

The findings demonstrate that National Guard soldiers have unique post-deployment social and material concerns that impair their mental health.

\section{Declaration of interest}

D.M and C.A.C. are full-time active component soldiers.
National Guard (NG) soldiers (reservists), who have deployed both to the Afghanistan and Iraq Wars, have received less research attention than their active component (regular soldier) counterparts even though there are indications, both from the USA and the UK, that they may be at greater risk for developing mental health problems. Two US studies have found that although National Guard and active component soldiers reported comparable levels of combat exposure and comparable rates of mental health problems immediately post-deployment, the National Guard soldiers had substantially worse mental health in the ensuing months, including higher rates of depression and post-traumatic stress disorder (PTSD) ${ }^{1,2}$ Findings from the UK show that reservists (who are comparable to US National Guard soldiers) had worse physical and mental health than regular soldiers (comparable to US active component soldiers), although they also reported higher levels of trauma exposure. ${ }^{3-5}$ There is some evidence that UK reserve soldiers are more likely than regular soldiers to experience major problems at home, including family problems, after Iraq deployments, ${ }^{3}$ which aligns with findings among US National Guard soldiers after the Persian Gulf War. ${ }^{6}$ One study also demonstrated that reserve component (includes National Guard soldiers) status conferred a higher risk of PTSD than active component status at 18-24 months after returning from the Persian Gulf War. ${ }^{7}$

It has been well established that combat exposure is associated with the risk of developing mental health problems among US service members who have deployed to Iraq and Afghanistan. ${ }^{1,8}$ Although National Guard soldiers have been extensively utilised in Iraq and Afghanistan, and have also served in prior conflicts such as the Persian Gulf War, ${ }^{9}$ scant attention has been paid to whether some of the unique challenges that they face as citizen soldiers confer additional risk, beyond combat exposure, for developing mental health problems. These soldiers, like most reserve component soldiers, are a unique group because their service to the military is predominantly part time. They serve within the USA and at times overseas while retaining their commitments to their civilian jobs. Consequently, involvement in protracted deployments, particularly in war zones, can disrupt National Guard soldiers' work lives in ways that might distinctly affect their mental health and well-being. A few studies have alluded to the stressful effects of transitioning from military employment to civilian employment among National Guard and reserve service members as a possible explanation for their higher rates of mental health problems ${ }^{1,4}$ or greater alcohol misuse. ${ }^{10}$ However, these studies did not directly examine National Guard specific variables. One study of National Guard soldiers who served in the Persian Gulf War included worry about civilian jobs and finances (operational definitions were omitted) as variables to examine their relationship to PTSD, but no association was found. ${ }^{11}$

Our study's main purpose is to examine whether issues salient to members of the National Guard are risk factors for developing a mental health problem. Adjusting for demographic variables and combat exposure we examine whether self-reported financial hardship, job loss, employer support, and the effect of deployment absence on co-workers are associated with depression and PTSD at 3 months and 12 months post-deployment. These factors can be included under the rubric of 'daily stressors. ${ }^{12}$ We will also examine whether all predictors have different effects based on the time since return from the war zone. We have not found any studies that have reported on the possible contribution of these National Guard specific issues to the development of mental health problems after Operation Enduring Freedom/Operation Iraqi Freedom deployments.

\section{Method}

\section{Sample and procedures}

The data for this study were obtained from National Guard soldiers from two brigades anonymously surveyed between 2005 and 2007 at approximately 3 months and 12 months after their deployments to Iraq. The survey procedures have been previously described. ${ }^{2,8,13}$ Recruitment briefings occurred in garrison at times 
convenient to the brigades. In total $94-99 \%$ of the soldiers who were present for the recruitment briefings gave consent. The soldiers that did not attend the briefings were absent for reasons such as medical or personal leave, training and other duties. Data were collected under a Walter Reed Army Institute of Research Institutional Review Board approved protocol. At 3 months 3127 National Guard soldiers gave content and at 12 months 2449 National Guard soldiers gave consent (5576 in total). Unit personnel indicated 8848 National Guard soldiers across the two brigades and times (approximately 5378 respondents at 3 months post-deployment and approximately 3470 respondents at 12 months post-deployment were available for the data collections). Therefore, the response rate at 3 and 12 months post-deployment is $58 \%(3127 / 5378)$ and $71 \%(2449 / 3470)$ respectively. Overall, the response rate is $63 \%(5576 / 8848)$, which is similar to the rates reported elsewhere. ${ }^{2,13,14}$ We restricted our sample to 4034 National Guard soldiers who reported that they had deployed only one time to Iraq (2539 at the first and 1495 at the second time point). This sample is a subset of the National Guard sample used by Thomas et $a l^{2}$ and, as reported by these authors, the demographics of National Guard soldiers in this sample are comparable with those of the population of National Guard soldiers that were screened after Iraq deployments.

\section{Measures}

\section{combat exposure}

This measure is a sum of 28 potentially traumatic combat exposure items that were consistent across the survey groups. The original response range one (never) to five (ten or more times) was recoded so that zero represented never and one represented at least once. The mean level of combat exposure reported at 3 and 12 months post-deployment was 13.77 and 14.15 events, respectively. The combat exposure of the National Guard soldiers was similar to that of active component soldiers. ${ }^{2}$

\section{PTSD and depression}

Post-traumatic stress disorder was assessed with the 17-item National Center for PTSD Checklist (PCL). ${ }^{15}$ To meet screening criteria for PTSD, respondents not only needed to have at least one intrusion, three avoidance and two hyperarousal symptoms but also have a score of at least 50 on a scale of 17 to $85 .^{2,8}$ The nine depression items of the Patient Health Questionnaire (PHQ-9) ${ }^{16}$ were used to evaluate major depression. To meet screening criteria for depression respondents had to endorse at least 5 symptoms, including 'feeling down, depressed or hopeless or having little interest in doing things for more than half the days in the past month' and indicate impairment in work, at home or in interpersonal functioning categorised at the 'very difficult' or 'extremely difficult' level.

\section{National Guard specific variables}

There were four National Guard specific variables. Soldiers were asked to respond to three of the items ('my most recent deployment caused me financial difficulties'; 'my employer currently supports my military affiliation'; and 'my absence during my most recent deployment/mobilisation negatively affected my co-workers at my civilian job') using a five-point Likert scale from strongly disagree to strongly agree. The fourth item required a yes or no response to 'I lost my civilian job following my most recent deployment/mobilisation'. Missing data for the four National Guard specific variables ranged from 3\% for the financial hardship question to $12 \%$ for the question about employer support of military affiliation whereas missing data for the other variables were between $<1$ and $1 \%$.

\section{Statistical analysis}

All analyses were performed with SPSS software (Version 13.0) for Windows. We used chi-squared analyses to assess the association between depression and PTSD rates at the two time points across the categories of the demographic variables and the four National Guard specific variables. For the three National Guard specific variables with Likert response scales the responses were collapsed to three levels (e.g. strongly agree and agree were combined). Separate logistic regression models are estimated per time point to assess the effect of the National Guard specific variables on depression and PTSD controlling for demographic variables and combat exposure. We also assessed whether the National Guard specific variables, the demographic variables and combat exposure varied in their associations with depression and PTSD at 12 months compared with 3 months post-deployment with predictor/time interactions. Preliminary analyses revealed that marital and parental status were unrelated to depression or PTSD so they were not included in the final logistic regression models. No substitutions were made for missing data; for both the chi-squared tests and logistic regression analyses missing data were deleted case-wise.

\section{Results}

The demographics of the sample are shown in Table 1. At both time points the samples were approximately 95\% male, over $50 \%$ were married and over $50 \%$ were parents. There were some minor differences across time in the samples. As expected, the 12-month sample was slightly older and of higher rank compared with the 3-month sample.

Table 2 displays the rates of depression and PTSD within each category of the demographic variables for both time points. As documented in Thomas et $a l^{2}$ and Kim et al ${ }^{13}$ National Guard soldiers' rates of screening positive for depression and PTSD were higher for most categories at the second time point compared with the first. For PTSD, overall rates tended to be much higher at both time points than what was found for depression. The PTSD-rate increases were greatest for 25- to 29-year-olds among the age groups, for males, for officers among the rank categories, for the never married among the marital status categories and for parents. Except for females and officers, all 12-month post-deployment PTSD rates for all groupings of National Guard soldiers were $>20 \%$.

Table 3 displays the percentage of National Guard soldiers who indicated their level of agreement to questions about financial difficulties, employer support of their military affiliation, and the negative effect of their deployment absence on their civilian co-workers as well as responses to whether or not they lost a job. This table also illustrates the percentage of National Guard soldiers who met screening criteria for depression and PTSD within the categories of the four National Guard specific variables. Overall, the majority of National Guard soldiers did not report that they experienced the National Guard specific issues. The proportion of soldiers who indicated that the deployment caused them financial difficulty was modest at both time points (17.3 and $19.8 \%$ respectively). About 1 in every 10 soldiers at either time indicated that they had experienced job loss, and slightly less than that proportion felt that their employer did not support their military affiliation. Around $16 \%$ of National Guard soldiers at 3 months, and approximately $18 \%$ at 12 months reported that their deployment absence had a negative impact on their co-workers.

The percentages of National Guard soldiers who reported adverse experiences (financial difficulties, job loss or unfavourable 


\begin{tabular}{|c|c|c|}
\hline \multirow[b]{2}{*}{ Characteristics } & \multicolumn{2}{|c|}{$\%(n)$} \\
\hline & $\begin{array}{l}3 \text { months } \\
(N=2539)\end{array}$ & $\begin{array}{l}12 \text { months } \\
(N=1495)\end{array}$ \\
\hline \multicolumn{3}{|l|}{ Age } \\
\hline $18-24$ & $33.4(843)$ & $28.1(419)$ \\
\hline $25-29$ & $19.2(485)$ & $20.5(306)$ \\
\hline $30-39$ & $29.5(744)$ & $31.3(466)$ \\
\hline$\geqslant 40$ & $17.8(449)$ & $20.1(299)$ \\
\hline \multicolumn{3}{|l|}{ Gender } \\
\hline Male & $94.8(2378)$ & 94.7 (1407) \\
\hline Female & $5.2(130)$ & $5.3(791)$ \\
\hline \multicolumn{3}{|l|}{ Rank } \\
\hline Junior enlisted & $52.9(1326)$ & $42.3(637)$ \\
\hline Non-commissioned officers & 42.0 (1053) & 49.5 (734) \\
\hline Officers & $5.1(127)$ & $8.2(121)$ \\
\hline \multicolumn{3}{|l|}{ Marital status } \\
\hline Never married & 32.8 (779) & $28.8(389)$ \\
\hline Married & $56.4(1342)$ & $59.5(804)$ \\
\hline Divorced/widowed & $10.8(257)$ & $11.7(158)$ \\
\hline \multicolumn{3}{|l|}{ Parental status } \\
\hline Yes & 54.7 (1182) & 60.4 (791) \\
\hline No & $45.3(977)$ & $39.6(518)$ \\
\hline
\end{tabular}

effects of their deployment on co-workers) or non-support of their military affiliation by employers had higher rates of both depression and PTSD (Table 3). For example, depression rates among National Guard soldiers who agreed that they had financial difficulties post-deployment were twice as high as among those who either answered neutrally or disagreed (9.3\% compared with 4.4 and $3.7 \%$ at 3 months; $14.7 \%$ compared with 4.9 and $6.5 \%$ at 12 months). Similarly, the PTSD rates of those who had lost jobs were at least twice as high compared with rates of those who had not $(27.8 \%$ compared with $13.3 \%$ at 3 months and $47.7 \% v$. $22.2 \%$ at 12 months).

The results of the logistic regression models to examine the multivariate association between the predictors and the two outcomes are shown in Table 4. Across both time points and for both outcomes, combat exposure was a significant predictor (for example, odds ratio OR $=1.06,95 \%$ CI $1.02-1.10$ for depression at 3 months and $\mathrm{OR}=1.23,95 \%$ CI $1.09-1.15$ for PTSD at 12 months).

None of the three lower age categories was a significant predictor of depression compared with the reference category at either 3 or 12 months. National Guard soldiers in the 18-24 age group were less likely to screen positive for PTSD than the $\geqslant 40+$ reference age group at 3 months $(\mathrm{OR}=0.56,95 \% \mathrm{CI}$ $0.35-0.91$ ) but not at 12 months. None of the National Guard soldiers within the other age groups was significantly more or less likely to screen positive for PTSD at either time point. Males were less likely to screen positive for depression $(\mathrm{OR}=0.36,95 \% \mathrm{CI}$ $0.16-0.84)$ and for PTSD (OR $=0.34,95 \%$ CI $0.19-0.62)$ than females at 3 months, but not at 12 months.

Junior enlisted soldiers, but not non-commissioned officers, were more likely than officers to screen positive for depression both at 3 months and at 12 months (OR $=9.32$, 95\% CI $1.24-$ 70.0; $\mathrm{OR}=3.57,95 \%$ CI 1.03-12.32 respectively). Junior enlisted soldiers (OR $=6.83,95 \%$ CI 2.65-17.58) and non-commissioned officers (OR $=3.81,95 \%$ CI $1.49-9.74)$ were more likely than officers to screen positive for PTSD at 3 months, but that was only true for junior enlisted soldiers at 12 months $(\mathrm{OR}=2.80,95 \% \mathrm{CI}$ 1.45-5.40). The confidence intervals are quite wide however, which indicates that the small sample size of the officer referent group may not have provided sufficient power for reliable contrasts. None of the time/predictor interactions were significant, which suggests that the predictor variables did not vary in their effects at 3 months compared with 12 months.

Experiencing financial difficulties was associated with depression at both 3 months ( $\mathrm{OR}=1.75,95 \%$ CI 1.06-2.90) and 12 months $(\mathrm{OR}=2.07,95 \%$ CI $1.16-3.67)$. It was also associated with PTSD at both $3(\mathrm{OR}=2.15,94 \%$ CI $1.56-2.97)$ and 12 $(\mathrm{OR}=1.64,95 \%$ CI $1.12-2.40)$ months. Job loss increased the likelihood of meeting criteria for depression at both 3 and 12 months $(\mathrm{OR}=2.29,95 \%$ CI $1.36-3.85$; OR $=2.26$, 95\% CI $1.29-$ 3.95 respectively), but only at 12 months for PTSD ( $\mathrm{OR}=1.96$, 95\% CI 1.27-3.02). Interestingly, both the soldiers who responded neutrally and those who disagreed with the statement 'my employer currently supports my military affiliation' were more likely to meet criteria for depression and PTSD at 3 months than the reference category. For PTSD at 3 months, the neutral

\begin{tabular}{|c|c|c|c|c|}
\hline \multirow[b]{2}{*}{ Characteristics } & \multicolumn{2}{|c|}{ Depression, \% $(n / N)$} & \multicolumn{2}{|c|}{ PTSD, \% $(n / N)$} \\
\hline & 3 months & 12 months & 3 months & 12 months \\
\hline \multicolumn{5}{|l|}{ Age } \\
\hline $18-24$ & $4.6(37 / 810)$ & $8.4(33 / 392)$ & $14.0(117 / 835)$ & $23.1(95 / 411)$ \\
\hline $25-29$ & $5.5(26 / 477)$ & $8.7(25 / 286)$ & $17.0(82 / 483)$ & $29.1(88 / 302)$ \\
\hline $30-39$ & $4.8(35 / 726)$ & $6.8(31 / 453)$ & $15.9(117 / 737)$ & $25.3(117 / 463)$ \\
\hline$\geqslant 40$ & $5.4(24 / 441)$ & $5.3(15 / 284)$ & $12.1(54 / 446)$ & $21.7(64 / 295)$ \\
\hline \multicolumn{5}{|l|}{ Gender } \\
\hline Male & $4.8(111 / 2314)$ & $7.3(98 / 1334)$ & $14.5(343 / 2360)$ & $25.1(348 / 1389)$ \\
\hline Female & $7.9(10 / 127)$ & $5.2(4 / 77)$ & $18.0(23 / 128)$ & $17.9(14 / 78)$ \\
\hline \multicolumn{5}{|l|}{ Rank } \\
\hline Junior enlisted & $6.1(78 / 1280)$ & $11.0(64 / 583)$ & $17.5(230 / 1312)$ & $28.3(174 / 615)$ \\
\hline Non-commissioned officers & $4.1(42 / 1034)$ & $5.1(36 / 706)$ & $12.6(132 / 1047)$ & $23.4(170 / 728)$ \\
\hline Officers & $<1 \%(1 / 125)$ & $2.5(3 / 118)$ & $4.7(6 / 127)$ & $15.8(19 / 120)$ \\
\hline \multicolumn{5}{|l|}{ Marital status } \\
\hline Never married & $3.9(261 / 774)$ & $7.8(30 / 385)$ & $12.3(96 / 779)$ & $22.1(86 / 389)$ \\
\hline Married & $5.2(70 / 1335)$ & $6.7(53 / 793)$ & $14.9(200 / 1338)$ & $24.6(197 / 800)$ \\
\hline Divorced/widowed & $5.9(15 / 255)$ & $10.2(16 / 157)$ & $17.5(45 / 257)$ & $26.1(41 / 157)$ \\
\hline \multicolumn{5}{|l|}{ Parental status } \\
\hline Yes & $5.5(65 / 1175)$ & $7.2(56 / 513)$ & $15.0(177 / 1180)$ & $25.8(203 / 787)$ \\
\hline No & $3.8(37 / 971)$ & $7.2(37 / 531)$ & $13.3(130 / 977)$ & $21.5(111 / 517)$ \\
\hline
\end{tabular}




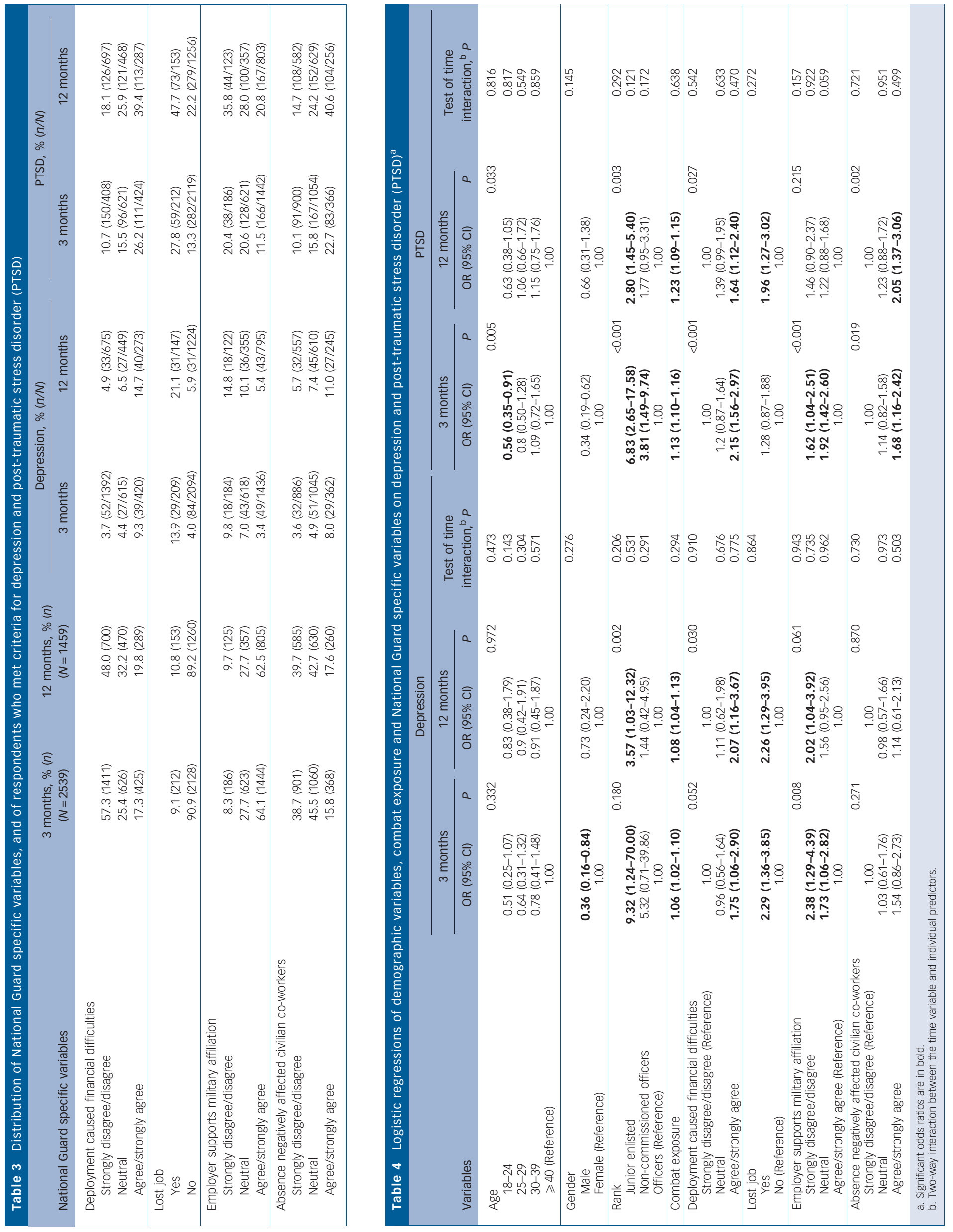


responders had slightly higher odds of meeting criteria $(\mathrm{OR}=1.92$, 95\% CI 1.42-2.60) than those who disagreed (OR $=1.62,95 \%$ CI 1.04-2.51). The perception that deployment absence had negatively affected co-workers was a significant predictor for PTSD, but not depression, at both time points $(\mathrm{OR}=1.68,95 \% \mathrm{CI}$ $1.16-2.42$; OR $=2.05,95 \%$ CI $1.37-3.06$ respectively).

\section{Discussion}

\section{Main findings}

A previous study ${ }^{2}$ showed that the rates of depression and PTSD among active component soldiers remained either fairly stable or increased modestly between 3 and 12 months post-deployment. However, the rates of these two disorders increased substantially more in National Guard soldiers. That study and a previous study ${ }^{1}$ offered explanations for the discrepancies in the rate increases in National Guard soldiers. We believe that our study's findings offer empirical evidence that the National Guard specific variables examined here are risk factors for developing post-deployment mental health problems after adjusting for combat exposure and demographic variables. They may explain why National Guard soldiers fare so much worse than active component soldiers at 12 months.

Consistent with both the civilian and military literature, both unemployment ${ }^{18-22}$ and subjective financial hardship ${ }^{21,23}$ are associated with poor psychological health. Financial hardship has sometimes been conceptualised as a mediator in the relationship between unemployment and poor mental health (not PTSD). ${ }^{21}$ That is, unemployment only leads to poor mental health when it results in financial hardship. Other studies have found financial hardship to be independently associated with depression. ${ }^{23}$ Likewise, this study shows that at 12 months postdeployment, both financial hardship and unemployment are independently associated with both depression and PTSD. Financial hardship also increases the likelihood, at 3 months, of screening positive for depression and PTSD. Unemployment, however, did not increase the likelihood of screening positive for PTSD at 3 months. A single item was used in this study to measure financial hardship, unlike the three- or four-item indices used in previous studies. Notwithstanding, financial hardship appears to be an important variable in the development of both depression and PTSD. We do not know whether the National Guard soldiers who lost their jobs were unemployed at the time of the survey or had experienced unemployment prior to it. It may be that, in line with Kessler et $a l^{19}$ current as well as prior unemployment negatively affected mental health.

It has been established that social support has salutary effects on the mental health of both military service personnel and civilians. ${ }^{20,24-26}$ Consistent with that literature, we found that National Guard soldiers who indicated that their employers did not support their military affiliation were more likely to meet criteria for depression (at both time points) and PTSD (at 3 months). An interesting finding was that National Guard soldiers who had a neutral response as to whether their employer supports their military affiliation were also more likely, at 3 months, to meet criteria for depression and PTSD. Perhaps the neutral response reflects ambivalence as to whether employers were supportive, and this ambivalence may be just as harmful as the perception that employers are unsupportive. Even more surprising is that, at 3 months, the likelihood of screening positive for PTSD was marginally greater for National Guard soldiers who gave a neutral response than for those who indicated that their employer did not support their military affiliation. It is unclear why this occurred, unless in this case ambivalence is actually more harmful.
What is it about employer support that is associated with depression or PTSD? Some authors have posited that negative social support contributes to the perception that the world is less safe, ${ }^{27}$ which may be compounded in soldiers with combat-related PTSD who have a heightened threat perception. For National Guard soldiers, feeling unsupported in the work environment, in which they likely spend a large part of their day, may contribute to less adaptive coping with post-deployment stress and higher rates of mental health problems. Another way of looking at this finding is that National Guard soldiers with mental health problems might have perceived the level of support from employers less favourably. A longitudinal study of the relationship between social support and PTSD in active component soldiers ${ }^{28}$ found that PTSD negatively affected the quality and quantity of social support; social support at time-point one did not reduce later PTSD symptom severity, but PTSD symptom severity at time-point one eroded social support at time-point two. The perception of lack of employer support may also be reflective of poor working relationships and other adverse working conditions such as employment discrimination, which National Guard soldiers have reported. ${ }^{29}$ However, we do not have the measures to assess this.

Also unhelpful for coping with PTSD appears to be the perception of National Guard soldiers that their deployment absence negatively affected their co-workers. We do not know whether National Guard soldiers felt concerned about this at the time of trauma exposures while they were deployed, nor to what degree there was an unpleasant work environment as a direct result of their absence and subsequent return to the workplace; an unpleasant work environment may also contribute to the perception that the world is hostile. ${ }^{27}$

\section{Limitations}

The findings of this study should be interpreted in light of some limitations. First, we do not have pre-deployment data on the mental health status of these National Guard soldiers. Without such longitudinal data, we are unable to assess whether depression or PTSD preceded or were a consequence of the National Guard specific stressors. For example, we were unable to assess whether having a mental health problem preceded job loss or vice versa, but we would expect that having a mental health problem would impede continuous employment. Although we have two data time points, the samples at 3 and at 12 months are cross-sectional not longitudinal ones. This limits examination of the effects over time of the National Guard specific variables.

A second limitation is that our measures of financial hardship and employer support were both single items, which may not provide as robust a measure of these constructs as multiple items would; however, some studies have shown that single items can be valid. ${ }^{30,31}$ Nonetheless, the consistent and significant associations of these variables with both depression and PTSD in this study suggest that their influence on the mental health of National Guard soldiers needs further examination.

Third, the samples for this study were drawn from surveys of two National Guard brigades. National Guard brigades, unlike active component brigades, likely reflect the demographic characteristics of the state in which they are located. Although this study's findings point to the importance of examining the mental health effects of the stressors that National Guard soldiers experience, generalising these findings to all National Guard soldiers who had deployed to Iraq should be done cautiously. However, the comparability of our samples to the post-deployment population of National Guard soldiers referenced in Thomas et $a l^{2}$ 
gives us some confidence that the results in a more representative sample of National Guard soldiers would be similar.

Lastly, there are several risk factors for both major depression and PTSD some of which could not be assessed in this manuscript. Major depression in particular is a complex disorder that is the consequence of many factors. Consequently, we do not know whether the four factors would be associated differently or not at all with depression or PTSD if other risk factors were included in our analyses. However, one study that presented a comprehensive model of major depression in men showed that both low social support and stressful life events were among the risk factors for this disorder. ${ }^{32}$ Likewise, lack of social support was also found in a meta-analysis to be a risk factor for PTSD in both civilian and military populations, whereas 'life stress' was associated with PTSD only among civilians. ${ }^{33}$ Given that the respondents in this study are 'citizen soldiers', it is likely that findings about life stress would also be applicable.

\section{Implications}

The results of this study provide substantial evidence that National Guard soldiers have unique concerns compared with active component soldiers, which affect their well-being. The findings also indicate that although combat exposure contributes to the development of mental health problems, other experiences are also important. Studies that examine mental health among service personnel who experienced combat also need to consider how social and material conditions (daily stressors) affect the mental health of these individuals. ${ }^{12}$ Although it is understood that National Guard soldiers are different from active component soldiers, little research has examined how the post-deployment work-related experiences of National Guard soldiers affect their well-being. This study shows that future research within this group of soldiers is needed to address this important gap. A better understanding of the factors that influence the mental health of these soldiers, especially in the period before their mental health disease rates exceed those of active component soldiers, will be instrumental in the prevention of mental health problems.

Lyndon A. Riviere, PhD, Center for Military Psychiatry and Neuroscience, Walte Reed Army Institute of Research, Silver Spring, Maryland; Athena Kendall-Robbins, MA, Defense and Veteran's Brain Injury Center/Defense Centers of Excellence, Rockville, Maryland; Dennis McGurk, PhD, United States Army Medical Research Unit-Europe, Heidelberg, Germany; Carl A. Castro, PhD, United States Army Medica Research and Materiel Command, Fort Detrick, Maryland; Charles W. Hoge, MD, Center for Military Psychiatry and Neuroscience, Walter Reed Army Institute of Center for Military Psychiatry and Neurosc
Research, Silver Spring, Maryland, USA

Correspondence: Lyndon A. Riviere, Center for Military Psychiatry \& Neuroscience, Walter Reed Army Institute of Research, 503 Robert Grant Avenue, Silver Spring, Maryland, MD 20910, USA. Email:

Iyndon.riviere@amedd.army.mil

First received 14 Jul 2010, final revision 17 Sep 2010, accepted 3 Nov 2010

\section{References}

1 Milliken CS, Auchterlonie JL, Hoge CW. Longitudinal assessment of mental health problems among active and reserve component soldiers returning from the Iraq war. JAMA 2007; 298: 2141-8.

2 Thomas JT, Wilk JE, Riviere LA, McGurk D, Castro CA, Hoge CW. The prevalence and functional impact of mental health problems among Active Component and National Guard soldiers 3 and 12 months following combat in Iraq. Arch Gen Psychiatry 2010; 67: 614-23.

3 Browne T, Hull L, Horn O, Jones M, Murphy D, Fear NT, et al. Explanations for the increase in mental health problems in UK reserve forces who have served in Iraq. Br J Psychiatry 2007; 190: 484-9.

4 Hotopf M, Hull L, Fear NT, Browne T, Horn O, Iversen A, et al. The health of UK military personnel who deployed to the 2003 Iraq war: a cohort study. Lancet 2006; 367: 1731-41.
5 Iversen AC, van Staden L, Hughes JH, Hughes JH, Browne T, Hull L, et al The prevalence of common mental disorders and PTSD in the UK military: using data from a clinical interview-based study. BMC Psychiatry 2009; 9: 68

6 Vogt DS, Samper RE, King DW, King LA, Martin JA. Deployment stressors and posttraumatic stress symptomatology: comparing active duty and national guard/reserve personnel from Gulf war I. J Trauma Stress 2008; 21: $66-74$.

7 Wolfe J, Erickson DJ, Sharkansky EJ, King DW, King LA. Course and predictors of posttraumatic stress disorder among Gulf war veterans: a prospective analysis. J Consult Clin Psychol 1999; 67: 520-8.

8 Hoge CW, Castro CA, Messer SP, McGurk D, Cotting DI, Koffman RL. Combat duty in Iraq and Afghanistan, mental health problems, and barriers to care. N Engl J Med 2004; 351:13-22.

9 National Guard Bureau. National Guard Fact Sheet: Army National Guard (FY2005). National Guard Bureau, 2006 (http://www.ng.mil/media/factsheets/ ARNG_Factsheet_May_06.pdf).

10 Jacobson IG, Ryan MAK, Hooper TI, Smith TC, Amoroso PJ, Boyko EJ, et al Alcohol use and alcohol-related problems before and after military combat deployment. JAMA 2008; 300: 663-75.

11 Holmes DT, Tariot PN, Cox C. Preliminary evidence of psychological distress among reservists in the Persian Gulf war. J Nerv Ment Dis 1998; 186: $166-73$.

12 Miller KE, Rasmussen A. War exposure, daily stressors, and mental health in conflict and post-conflict settings: bridging the divide between trauma-focused and psychosocial frameworks. Soc Sci Med 2010; 70: 7-16.

13 Kim PY, Thomas JL, Wilk JE, Hoge CW, Castro CA. Stigma and barriers to care and the utilization of mental health care in active duty and National Guard Component soldiers following combat. Psychiatr Serv 2010; 61: 582-8.

14 Wilk JE, Thomas JT, McGurk D, Riviere LA, Castro CA, Hoge CW. Mild traumatic brain injury (concussion) during combat. Lack of association of blast mechanism with persistent postconcussive symptoms. J Head Trauma Rehabil 2010; 25: 9-14.

15 Weathers FW, Litz BT, Herman DS, Huska JA, Keane TM. The PTSD Checklist (PCL): Reliability, Validity, and Diagnostic Utility. Paper presented at: 9th Annual Meeting of International Society for Traumatic Stress Studies, October1993 (http://www.pdhealth.mil/library/downloads/ PCL_sychometrics.doc).

16 Spitzer RI, Kroenke K, Williams JB. Validation and utility of a self-report version of PRIME-MD: the PHQ primary care study. JAMA 1999; 282 1737-44.

17 American Psychiatric Association. Diagnostic and Statistical Manual of Mental Disorders (4th edn, revised) (DSM-IV-TR). APA, 2000.

18 McKee-Ryan FM, Song Z, Wanberg CR, Kinicki AJ. Psychological and physical well-being during unemployment: a meta-analytic study. J Appl Psychol 2005; 90: 53-76.

19 Kessler RC, House JS, Turner JB. Unemployment and health in a community sample. J Health Soc Behav 1987; 28: 51-9.

20 Vinokur A, Caplan RD, Williams CC. Effects of recent and past stress on mental health: coping with unemployment among Vietnam veterans and nonveterans. J Appl Soc Psychol 1987; 17: 710-30

21 Kessler RC, Turner JB, House JS. Effects of unemployment on health in a community survey. Main, modifying, and mediating effects. J Soc Issues 1988; 44: 69-85.

22 Zatzick DF, Marmar CR, Weiss DS, Browner WS, Metzler TJ, Golding JM, et al. Posttraumatic stress disorder and functioning and quality of life outcomes in a nationally representative sample of male Vietnam veterans. Am J Psychiatry 1997; 154: 1690-5.

23 Butterworth P, Rodgers B, Windsor TD. Financial hardship, socio-economic position and depression: results from the PATH Through Life Survey. Soc Sci Med 2009; 69: 229-37.

24 Pietrzak RH, Johnson DC, Goldstein MB, Malley JC, Southwick SM. Psychological resilience and postdeployment social support protect against traumatic stress and depressive symptoms in soldiers returning from Operations Enduring Freedom and Iraqi Freedom. Depress Anxiety 2009; 26 745-51.

25 Ozer EJ, Best SR, Lipsey TL, Weiss DS. Predictors of posttraumatic stress disorder and symptoms in adults: a meta-analysis. Psychol Bull 2003; 129 $52-73$.

26 Laffaye C, Cavella S, Drescher K, Rosen C. Relationship among PTSD symptoms, social support, and support source in veterans with chronic PTSD. J Traum Stress 2008; 21: 394-401.

27 Charuvastra A, Cloitre M. Social bonds and posttraumatic stress disorder. Annu Rev Psychol 2008; 59: 301-28. 
28 Defense Manpower and Data Center (DMDC). Status of Forces Survey of Reserve Component Members. DMDC, 2004 (http://www.dod.gov/pubs/foi/ personnel/07-F-2315_SOFS-Reserves20071203.pdf).

29 King DW, King LA, Taft C, Hammond C, Stone ER. Directionality of the association between social support and posttraumatic stress disorder: a longitudinal investigation. J Appl Soc Psychol 2006; 36: 2980-92.

30 Elo A-L, Leppanen A. Can a single item measure of stress be valid? Work Stress 2000; 14: 192-3.
31 Wanous JP, Reichers AE, Hudy MJ. Overall job satisfaction: how good are single-item measures? J Appl Psychol 1997; 82: 247-52.

32 Kendler, KS, Gardner, CO, Prescott, CA. Toward a comprehensive developmental model of major depression in men. Am J Psychiatry 2006; 163: $115-24$.

33 Brewin, CR, Andrews, B, Valentin, JD. Meta-analysis of risk factors for posttraumatic stress disorder in trauma-exposed adults. J Consult Clin Psychol 68: 748-66.

\section{psychiatry in the Old Testament}

\section{Morbid jealousy may have been recognised in the Old Testament}

\section{George Stein}

The Book of Numbers describes a horrific punishment called the sotah for women who were unfaithful to their husbands. The priest puts some curses in writing, dishevels the woman's hair and makes her drink the 'water of bitterness' (a mixture of dust with holy water), which gives her severe abdominal pain. As a consequence, her womb discharges, her uterus drops and she may be rendered infertile. Women who have not been unfaithful will retain their fertility despite this procedure. For further details of the sotah the reader is referred to Num. 5:16-28.

But how is the unfaithful wife doomed to the punishment of the sotah to be identified? There appear to be three separate categories of infidelity: (1) undiscovered but true infidelity; (2) discovered and true infidelity; (3) suspicion of infidelity where the wife has not been unfaithful.

Num. 5:12 'If any man's wife goes astray and is unfaithful to him, 13 if a man has had intercourse with her but it is hidden from her husband, so that she is undetected, though she has defiled herself and there is no witness against her since she was not caught in the act; 14 if a spirit of jealousy comes on him and he is jealous of his wife who has herself defiled herself; 15 or if a spirit of jealousy comes on him and he is jealous of his wife, though she has not defiled herself then the man shall bring his wife to the priest'.

In this passage, v. 15 is the critical verse suggestive of morbid jealousy and it is of great interest that the more recent translations of the Bible use the word suspicion instead of 'spirit of jealousy' in this passage.

Thus the Moffatt Bible (translated in 1941) has: 'if he has a fit of suspicion [emphasis added], suspecting his wife even although she may not have defiled herself, he must take his wife before the priest ...'

The New International Version (translated 1973) has: 'or if he is jealous or suspects her [emphasis added] even though she is not impure - then he is to take his wife to the priest...'

The Jerusalem Bible (translated from Hebrew into French and then into English, 1973) has: 'or again if this spirit of suspicion comes over him [emphasis added] and makes him suspicious of his wife even when she is innocent - the man will bring his wife before the priest'

Such a description is remarkably close to the concept of morbid jealousy. The ancient Israelites clearly recognised that the suspicion of jealousy was the main problem and that even if such suspicions were false, suspicious men needed urgent mollification, as described later in the chapter. From the Moffatt Bible:

5:29 'Such is the ritual in cases of suspicion, when a woman has gone astray and made herself unclean while under her husband's authority, 30 or when a spirit of suspicion has come over a man and made him suspicious of his wife. When a husband brings such a woman before Yahweh, the priest will apply this ritual in full. 31 The husband will be guiltless, but the woman shall bear the consequences of her guilt.'

The ancient Israelites seem to have recognised that men afflicted by such suspicions (whether founded or unfounded) could not be ignored. Morbid jealousy is currently classified as one of the delusional disorders and is recognised as a dangerous condition, sometimes even associated with homicide. In the ancient world, it was the woman who bore the brunt of the punishment, even when she had done nothing wrong and only formed the focus of the man's delusional jealousy. Today there has been a small advance in that the women are no longer blamed for this condition, but in a difficult case a marital separation is still sometimes the only available treatment option. 